\title{
The Ligation of Intersphincteric Fistula Tract Technique: A Preliminary Experience
}

\author{
Pasquale Cianci, Nicola Tartaglia, Alberto Fersini, Libero Luca Giambavicchio, Vincenzo Neri, \\ Antonio Ambrosi \\ Department of Medical and Surgical Sciences, University of Foggia, Foggia, Italy
}

Purpose: Surgery is the only treatment for anal fistula. Many surgical techniques have been described. The aim of this study was to communicate the authors' preliminary experience in the use of a recently proposed, simplified technique. Methods: This was a prospective study of 28 patients admitted from January 13, 2016 through July 20, 2017. Patients were managed with the ligation of intersphincteric fistula tract (LIFT) technique and results were observed and documented, including recurrence rate, incontinence rate, and other postoperative complications.

Results: A total of 28 patients were studied. The mean operation time was 31 minutes (range, 23-44 minutes), and there were no intra- and postoperative complications. The overall complete healing rate was $85.7 \%$, and the recurrence rate was $14.2 \%$. Follow-up was conducted at 1,3, and 6 months.

Conclusion: Many surgical techniques have been described for the treatment of anal fistula. The correct choice of surgical technique out of available procedures is the most important factor for proper treatment and reducing the risk of recurrence or incontinence. In the authors' experience, the LIFT technique is simple and easy to learn, and is a good choice for the treatment of simple anal fistula; however, a tailored surgery remains the gold standard for this condition.

Keywords: LIFT procedure; Fistula in ano; Coloproctology; Complex fistula; Anal disease

\section{INTRODUCTION}

Perianal abscess and fistula are two different moments of the same disease. In a recent review the incidence rate of fistula formation after a perianal abscess is $26 \%-37 \%$ [1]. Zanotti et al. [2] conclude that the incidence of fistula-in-ano in the EU, according to the data obtained of four European countries, ranges from 1.20 to 2.80 per 10,000 inhabitants per year. The conditions are characterized by a chronic infection with purulent discharge and cyclical pain associated with purulent material reaccumulation and a next intermittent spontaneous decompression [3]. Fistula-in-ano refers

Received: April 27, 2018 • Accepted: August 16, 2018

Correspondence to: Pasquale Cianci, M.D.

Department of Medical and Surgical Sciences, University of Foggia, Luigi

Pinto str, 1, Foggia, Italy

Tel \& Fax: +390881733808, E-mail: ciancidoc1@virgilio.it.

ORCID code: https://orcid.org/0000-0003-2839-2520

(C) 2019 The Korean Society of Coloproctology

This is an open-access article distributed under the terms of the Creative Commons Attribution NonCommercial License (http://creativecommons.org/licenses/by-nc/4.0) which permits unrestricted non-

commercial use, distribution, and reproduction in any medium, provided the original work is properly cited. to a communication between the anal canal and the perianal region due to a cryptoglandular infection. Parks et al. [4] have ranked fistulae into: superficial, intersphincteric, transsphincteric, suprasphincteric, or extrasphincteric based on anatomical origin, route, and external opening. Surgery is the only way to treat a fistula [5]; however, possible damage to the sphincter apparatus with alteration of continence may compromise the outcomes [6]. The current operative treatment of more complex fistulae (high fistulae whose tract crosses more than $30 \%-50 \%$ of the external sphincter, recurrent or complex fistulae with multiple extensions, women with anterior fistula or previous obstetric injury, patients with pre-existing incontinence, and patients with coexisting Crohn disease) is frequently followed by a long and complicated postoperative course [7]. The ligation of intersphincteric fistula tract (LIFT) technique is a recently developed approach for the treatment of fistula-in-ano. This procedure involves the secure closure of the internal and external opening and removal of infected cryptoglandular tissue via an intersphincteric approach [8, 9]. The aim of this study was to communicate our preliminary experience in the use of a recently proposed, simplified technique. 


\section{METHODS}

In the authors' Surgical Department within a University hospital, from January 13, 2016 through July 20, 2017 the authors conducted a prospective observational study of 28 consecutive patients. IRB was not proceeded because corporate ethics committee was not installed yet, but, we obtained informed consent from patients. Patients were enrolled during an outpatient visit, during which a detailed history was collected and a physical examination was performed; continence was evaluated with the Wexner score (Table 1). Patients with complex fistula-in-ano, superficial fistulas that could be treated by simple fistulotomy, inflammatory bowel disease and anorectal tumor or history of malignancies were excluded from the study. Subsequently the patients were studied in preadmission, during which they performed instrumental diagnostic exams: blood tests, chest X-ray, cardiological visit, and finally colonoscopy, and endoanal ultrasonography combined with hydrogen-peroxide injection for fistula classification (Table 2). All patients were operated upon using the LIFT procedure, in the lithotomic position, under spinal anesthesia, and in 1 day of hospitalization. Preoperative preparation consisted of a rectal enema the evening before surgery, and antibiotic prophylaxis with $2 \mathrm{~g}$ of ceftriaxone 2 hours before the operation. All the interventions followed the same procedure: (1) manual anal divulsion, (2) insertion of anoscope and consequently identification of the internal opening by injection of water through the external opening or by metallic probe (Fig. 1), (3) curvilinear incision of $2.5 \mathrm{~cm}$ at the intersphincteric groove overlying the fistula tract, (4) dissection in the intersphincteric plane, (5) isolation of the intersphincteric tract of the fistula (Fig. 2), (6) suture of its internal opening with a 3-0 polyglactine knot, (7) section of the remaining intersphinc-

Table 1. Demographic data $(\mathrm{n}=28)$

\begin{tabular}{lc}
\hline Variable & Value \\
\hline Age $(\mathrm{yr})$, mean (range) & $42.2(28-70)$ \\
Sex & \\
$\quad$ Male & 19 \\
$\quad$ Female & 9 \\
Body mass index $\left(\mathrm{kg} / \mathrm{m}^{2}\right)$, mean (range) & $24.3(18.6-30)$ \\
Prior surgery & 0 \\
Preoperative incontinence & 0 \\
\hline
\end{tabular}

Table 2. Type of fistula

\begin{tabular}{lc}
\hline Type & No. of cases (\%) \\
\hline Transsphincteric & $21(75.0)$ \\
Intersphincteric & $3(10.8)$ \\
Recto-vaginal & $2(7.1)$ \\
Transsphincteric/unknown recto-vaginal component & $2(7.1)$ \\
\hline
\end{tabular}

teric tract, which is then removed and presented for pathological examination (Fig. 3), (8) confirmation of the removal of the correct fistula tract was performed with metal probe, (9) removal of the granulation tissue in the rest of the fistula by curette, (10) closure of the incision along the intersphincteric groove with a few interrupted stitches of 3-0 polyglactin (Fig. 4).

After the operation, no dietary restriction has been imposed. The patients were advised to self-care their wounds by cleansing with amuchin solution diluted to $0.05 \%$. No postoperative antibiotic therapy was given to any patient. Follow-up was conducted at 1, 3 and 6 months, and during these periods postoperative incontinence, persistence or recurrence of the disease and the presence of late complications were evaluated.

\section{RESULTS}

Of the 28 patients observed there were 19 males and 9 females

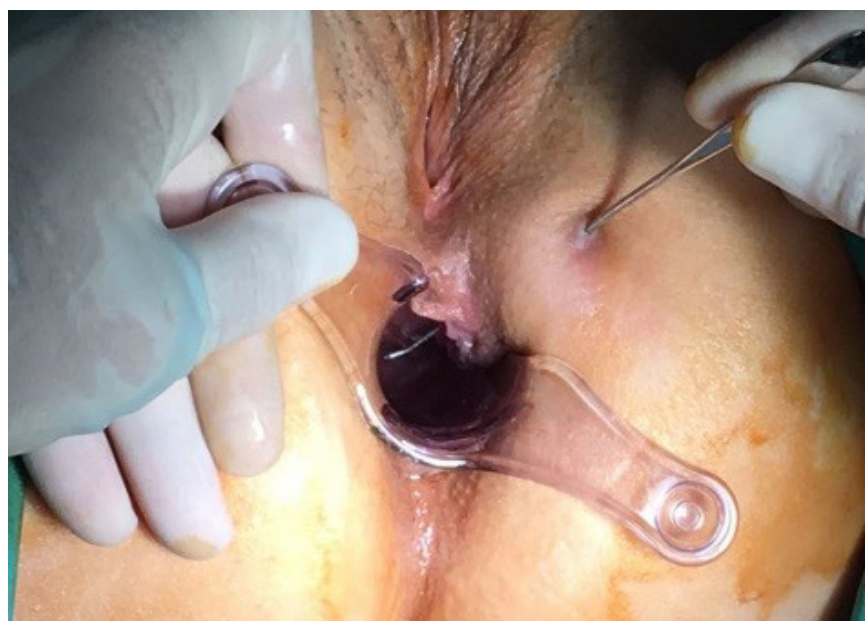

Fig. 1. Identification of the internal opening.

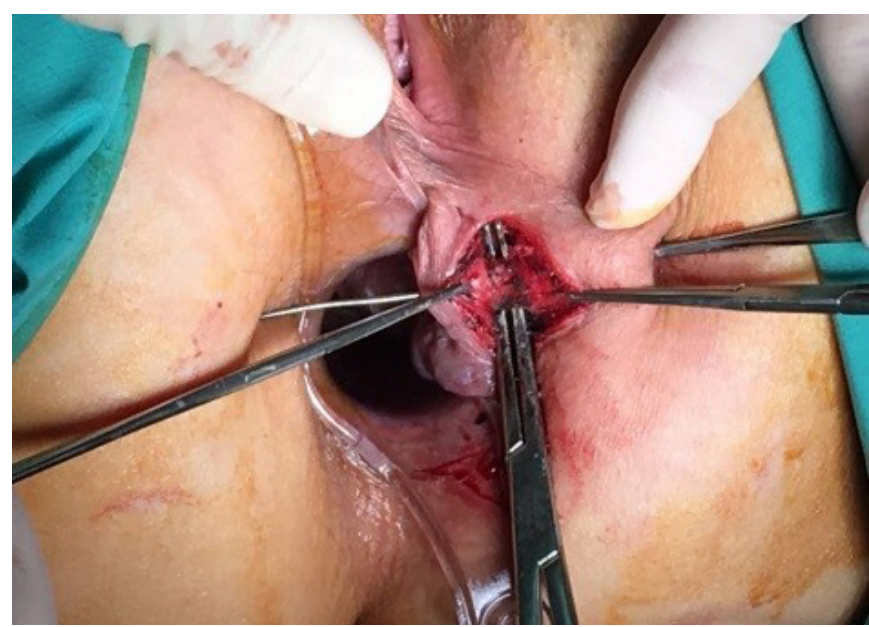

Fig. 2. Isolation of the intersphincteric tract. 


\section{Coloproctology

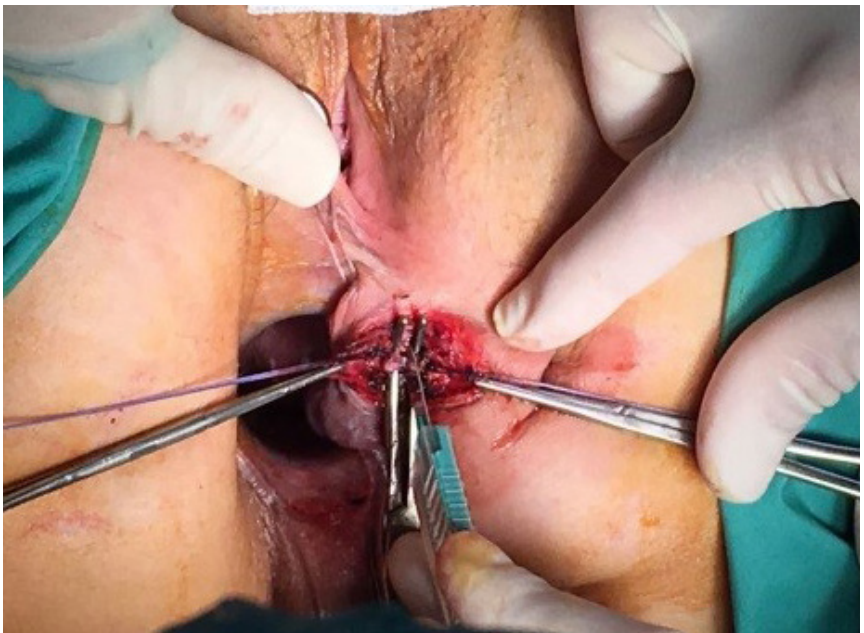

Fig. 3. Section of the intersphincteric tract.

with an average age of 42.2 years (range, $28-70$ years). The average value of the BMI was $24.3 \mathrm{~kg} / \mathrm{m}^{2}$ (range, $18.6-30 \mathrm{~kg} / \mathrm{m}^{2}$ ), none had previous specific surgical procedures and no preoperative incontinence was found in any patient (Wexner score) (Table 1). Classification by type of fistula showed 23 transsphincteric fistulas, 2 of these also had a recto-vaginal component not shown on preoperative exams, 3 intersphincteric fistulas, and 2 single rectovaginal types (Table 2). Table 3 summarizes the intra- and postoperative outcomes. All operations were completed by the same team of surgeons, and mean operation time was 31 minutes (range, 23-44 minutes). There were no intra- and postoperative complications, and the median duration of hospitalization was 1.0 days (range, 1-2 days). All patients were discharged the day after surgery, only in 1 case the duration of hospitalization was 2 full days because the patient had a fever resolved with paracetamol. Wound healing on average occurred in 4 weeks (range, 3-5 weeks). The overall complete healing rate was $85.7 \%$, on the other hand the recurrence rate was $14.2 \%$ and involved 4 patients with transsphincter fistula. These recurrences occurred during the follow-up period and involved 2 females who had a recto-vaginal component and 2 males with complex high transsphinteric fistula, probably not recognized by the preoperative exams. These cases were successfully treated later with a seton.

\section{DISCUSSION}

Surgery is the only treatment of anal fistula [5]. Many surgical techniques have been described, including the use of seton, fibrin glue, collagen plugs, rectal advancement flaps, fistulotomy with sphincter repair, and rerouting the fistula tract [10]. However, the correct technique choice, based on specific pathological characteristics of the lesion, among the possible surgical procedures is most important for proper treatment and to reduce the risk of recurrence or incontinence. Ligation of the intersphincteric fistula

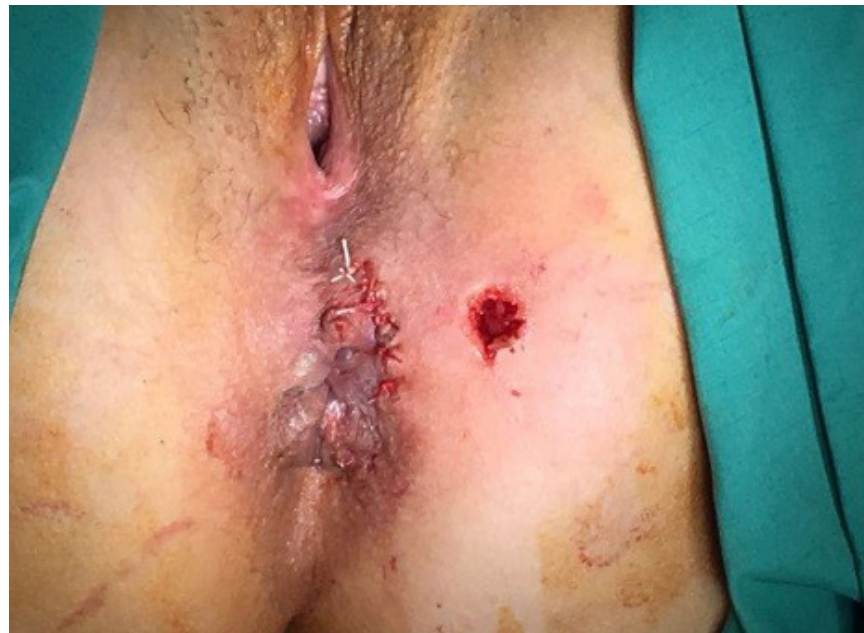

Fig. 4. Closure of the incision along the intersphincteric groove.

Table 3. Intraoperative and postoperative outcomes

\begin{tabular}{lc}
\hline Variable & Value \\
\hline Operative time (min), mean (range) & $31(23-44)$ \\
Intraoperative complications & 0 \\
Postoperative incontinence & 0 \\
Postoperative complications & 0 \\
Hospital stay (day), median (range) & $1.0(1-2)$ \\
Wound healing time (wk), mean (range) & $4(3-5)$ \\
Healing rate, $n(\%)$ & $24 / 28(85.7)$ \\
Recurrence, $n$ (\%) & $4 / 28(14.2)$ \\
Time to recurrence (wk), mean (range) & $5.2(4-7)$ \\
\hline
\end{tabular}

tract was first described by Rojanasakul et al. [9] and was found to be a simple, safe, and cost-effective treatment option $[11,12]$. This technique involves disconnection of the internal opening from the fistula tract at the level of the intersphincteric plane and removal of the residual infected glands, without dividing any part of the anal sphincter complex. Following the identification of the internal opening by injecting hydrogen peroxide from the external opening or gently probing the fistula tract, a 3- to 4-cm curvilinear incision along the anal margin is performed at the site of the fistula and the intersphincteric plane is entered. In a systematic review of 13 articles including 438 patients with fistula, the overall success rate ranged from $40 \%$ [13] to $94.4 \%$ [9], with a pooled success rate of $71 \%$ [14]. Several variations of the original LIFT technique have since been reported. The addition of fistulectomy of the external tract resulted in a success rate of $82 \%[13,15]$. Closure of the internal orifice by suture or advancement flap has not yielded better results (68\%) [16]. Adding bioabsorbable mesh interposition was successful in 93.5\% [17] and insertion of a fistula plug was successful in 95\% [18]. The LIFT has the advantages of 
minimal impairment of continence (6\%) [19] and the potential to convert a high fistula to an intersphincteric one even in the case of failure $[14,18,20]$. Historically we have treated the anal fistulas with the seton, approaching a new technique we preferred to exclude complex cases (e.g., high fistulas), in this preliminary experience we have followed the initial indications of the first author [9]. Our results, although they concern a small number of cases, are similar to international literature and show that the healing rate is $85.7 \%$. Murugesan et al. [21] have provided a narrative synthesis of the findings from the 22 studies; no incontinence or change in continence were reported in 18 of 22 studies analyzed. Similarly, in this prospective study, we have observed no patients with incontinence after LIFT procedure. According to the literature, LIFT procedure has the advantages of preservation of the anal sphincters, minimal tissue injury, short healing time with no additional costs. In case of failure, the procedure can be readily repeated. However, to date, there is only one prospective-randomized trial and most of the evidence relies on small case-series with variable follow-up and no objective assessment of incontinence.

In conclusion, many surgical techniques have been described for the treatment of anal fistula. The correct choice of surgical technique among the possible surgical procedures remains the most important point for proper treatment and to reduce the risk of recurrence or incontinence. In our experience LIFT technique is simple and easy to learn, and represents a good choice for the treatment of simple anal fistula but a tailored surgery remains the gold standard for this disease.

\section{CONFLICT OF INTEREST}

No potential conflict of interest relevant to this article was reported.

\section{REFERENCES}

1. Malik AI, Nelson RL, Tou S. Incision and drainage of perianal abscess with or without treatment of anal fistula. Cochrane Database Syst Rev 2010;(7):CD006827.

2. Zanotti C, Martinez-Puente C, Pascual I, Pascual M, Herreros D, García-Olmo D. An assessment of the incidence of fistula-in-ano in four countries of the European Union. Int J Colorectal Dis 2007;22:1459-62.

3. Whiteford MH, Kilkenny J 3rd, Hyman N, Buie WD, Cohen J, Orsay $\mathrm{C}$, et al. Practice parameters for the treatment of perianal abscess and fistula-in-ano (revised). Dis Colon Rectum 2005;48: 1337-42.

4. Parks AG, Gordon PH, Hardcastle JD. A classification of fistulain-ano. Br J Surg 1976;63:1-12.

5. Abbas MA, Jackson CH, Haigh PI. Predictors of outcome for anal fistula surgery. Arch Surg 2011;146:1011-6.
6. Parks AG, Stitz RW. The treatment of high fistula-in-ano. Dis Colon Rectum 1976;19:487-99.

7. Abcarian H. Anorectal infection: abscess-fistula. Clin Colon Rectal Surg 2011;24:14-21.

8. Rojanasakul A. LIFT procedure: a simplified technique for fistula-in-ano. Tech Coloproctol 2009;13:237-40.

9. Rojanasakul A, Pattanaarun J, Sahakitrungruang C, Tantiphlachiva K. Total anal sphincter saving technique for fistula-in-ano; the ligation of intersphincteric fistula tract. J Med Assoc Thai 2007; 90:581-6.

10. Wong S, Solomon M, Crowe P, Ooi K. Cure, continence and quality of life after treatment for fistula-in-ano. ANZ J Surg 2008;78: 675-82.

11. Steele SR, Kumar R, Feingold DL, Rafferty JL, Buie WD; Standards Practice Task Force of the American Society of Colon and Rectal Surgeons. Practice parameters for the management of perianal abscess and fistula-in-ano. Dis Colon Rectum 2011;54: 1465-74.

12. Shanwani A, Nor AM, Amri N. Ligation of the intersphincteric fistula tract (LIFT): a sphincter-saving technique for fistula-inano. Dis Colon Rectum 2010;53:39-42.

13. Wallin UG, Mellgren AF, Madoff RD, Goldberg SM. Does ligation of the intersphincteric fistula tract raise the bar in fistula surgery? Dis Colon Rectum 2012;55:1173-8.

14. Hong KD, Kang S, Kalaskar S, Wexner SD. Ligation of intersphincteric fistula tract (LIFT) to treat anal fistula: systematic review and meta-analysis. Tech Coloproctol 2014;18:685-91.

15. Aboulian A, Kaji AH, Kumar RR. Early result of ligation of the intersphincteric fistula tract for fistula-in-ano. Dis Colon Rectum 2011;54:289-92.

16. van Onkelen RS, Gosselink MP, Schouten WR. Is it possible to improve the outcome of transanal advancement flap repair for high transsphincteric fistulas by additional ligation of the intersphincteric fistula tract? Dis Colon Rectum 2012;55:163-6.

17. Ellis CN. Outcomes with the use of bioprosthetic grafts to reinforce the ligation of the intersphincteric fistula tract (BioLIFT procedure) for the management of complex anal fistulas. Dis Colon Rectum 2010;53:1361-4.

18. de Parades V, Zeitoun JD, Atienza P. Cryptoglandular anal fistula. J Visc Surg 2010;147:e203-15.

19. Voelzke BB, McAninch JW, Breyer BN, Glass AS, Garcia-Aguilar J. Transperineal management for postoperative and radiation rectourethral fistulas. J Urol 2013;189:966-71.

20. Gingold DS, Murrell ZA, Fleshner PR. A prospective evaluation of the ligation of the intersphincteric tract procedure for complex anal fistula in patients with Crohn's disease. Ann Surg 2014;260: 1057-61.

21. Murugesan J, Mor I, Fulham S, Hitos K. Systematic review of efficacy of LIFT procedure in crpytoglandular fistula-in-ano. J Coloproctol 2014;34:109-19. 